\title{
Pirárselas: subjetivación y analogía ${ }^{1}$
}

\author{
Pirárselas: subjectification and analogy
}

\author{
José Luis Cifuentes Honrubia \\ Universidad de Alicante
}

\begin{abstract}
Resumen. Para la RAE (2009), un grupo numeroso de locuciones verbales contiene pronombres personales átonos, casi siempre lo, la o las, cuyo referente a veces se intuye contextualmente, pero queda sin especificar en la mayor parte de los casos: es el llamado complemento directo lexicalizado. Dado su particular comportamiento, estas construcciones normalmente son consideradas dentro de los estudios de fraseología como un tipo de locuciones con clítico y suponen un gran interés por la interrelación entre léxico, sintaxis y morfología que implican. Tradicionalmente también se ha planteado la necesidad de un estudio histórico para intentar desentrañar la referencia oculta de los clíticos en estas construcciones fosilizadas. En este trabajo presentaré el caso de pirárselas (a partir de los datos de CORDE y CREA), particularmente interesante por cuanto parece mostrar una extraña compatibilidad sintáctica del constituyente representado por el clítico, pues resulta muy extraño considerar que un uso intransitivo verbal, indicando desplazamiento del sujeto, pueda combinarse con un clítico femenino plural que señala complemento directo: no parece haber ningún tipo de correferencialidad posible para las. En nuestra propuesta vamos a demostrar que dicha correferencialidad existe y permitirá aclarar sin ambages el significado de la construcción. El recorrido histórico que efectuaremos nos obligará a estudiar también el caso de otras construcciones con significado similar, como tomarlas, afufarlas, apeldarlas, liarlas, volarlas, guillárselas y tocárselas. Nos serviremos de conceptos metodológicos como subjetivación y analogía para explicar lo sucedido con la presencia del clítico femenino en estas construcciones.
\end{abstract}

Palabras clave: clítico, locución, gramaticalización, subjetivación, analogía.

Data de recepción: 25-12-2017 - Data de aceptación: 15-04-2018.

1 El presente trabajo se inscribe dentro del proyecto de investigación FFI2017-85441-R, financiado por el Ministerio de Economía y Competitividad. 


\begin{abstract}
According to the Academic Grammar (RAE 2009), a considerable number of verbal phraseological units contain unstressed personal pronouns (usually lo, la or las), whose referent can sometimes be contextually identified but remains unspecified in most cases: they are typically known as cases of lexicalized direct objects. From the point of view of phraseology, these constructions are usually considered a type of 'expression with a clitic', and they have always been found interesting because of the interactions between lexicon, syntax and morphology involved. In addition the need has been felt for historical studies unraveling the hidden reference of the clitics in these fossilized constructions. In this paper, I analyze the case of pirárselas using data from the corpora CORDE and CREA. This case is particularly interesting because it seems to show an unexpected syntactic compatibility of the constituent represented by the clitic; specifically, it is quite strange that an intransitive verbal meaning indicating motion of the subject can be combined with a plural female clitic that represents a direct object, and there does not seem to be any type of possible correferentiality for las. Nevertheless, I demonstrate that such a correferentiality does exist and that, in fact, it allows us to unambiguously clarify the meaning of the construction. The historical analysis that I develop requires to take into account other constructions with simlar meanings as well, such as tomarlas, afufarlas, apeldarlas, liarlas, volarlas, guillárselas and tocárselas. I explain the functioning of the female clitic in these constructions using methodological concepts such as subjectification and analogy.
\end{abstract}

Keywords: clitic, phraseological unit, grammaticalization, subjectification, analogy.

\title{
1. INTRODUCCIÓN: LOCUCIONES VERBALES CON CLÍTICO FOSILIZADO
}

Señala la RAE (2009: 2649-2654) que, dentro de las numerosas locuciones verbales formadas con verbos transitivos, hay un grupo que contiene pronombres personales átonos cuyo referente no suele estar especificado en la mayor parte de los casos, sino que viene dado por el contexto. Los clíticos a los que hace referencia la RAE son $l o$, la y las, es decir, se trata de complementos directos lexicalizados en la función de complemento directo: dormirla, deberla, etc. Y, según la RAE, suelen ser propias del registro coloquial.

La Fraseología suele mencionar estas locuciones. Así, por ejemplo, García Page (2008: 340-342) analiza las locuciones con clítico de objeto directo sin referente nominal expreso, y señala que es difícil reconocer sincrónicamente el referente de tales locuciones, e incluso aunque se intuya, puede ser difícil su verificación. Destaca García Page, igualmente, que la mayoría de las locuciones adopta las formas femeninas, ya sea en singular o en plural, lo cual parece estar en consonancia con otras locuciones. La causa de esta preponderancia del femenino se ha tratado de explicar por dos razones: 
a) la transformación en femenino plural de algunos neutros latinos (Casares 1969: 240), y b) el valor gramatical del término marcado femenino (Delbecque 1997).

La propuesta de Casares es interesante, por cuanto son abundantes y conocidos los ejemplos de colectivos que adoptan la forma femenina singular: leña, herramienta, nómina, etc. Y señala como ejemplo el caso de boda, procedente de uotum, plural uota, que al no transparentar claramente el significado colectivo parece haber propiciado el plural bodas para restablecer la idea de conjunto. La propuesta es interesante y no exenta de justificación. En realidad, parece haber sido Spitzer (1941: 352) quien señala por primera vez la relación, y comenta que el carácter familiar, supongo que coincidente con la idea de 'coloquial' de la RAE, proviene de la elipsis del sustantivo, pues el hablante se comporta como si el interlocutor supiera la referencia de esos pronombres confidenciales.

Mariner ha desarrollado la idea anterior, y plantea que el neutro en las lenguas románicas señala la desindividualización (1973: 34), queriendo significar con ello la idea de indeterminación, abstracción, colectivización, etc., frente a la individualización (determinación, concreción, etc.) propia del masculino y femenino considerados conjuntamente; es decir, el neutro parece abocado a la designación de lo conceptual y abstracto, lo cual puede ser indeterminado o no. Además, según Mariner (1968: 1304), al ser el femenino el término marcado de la oposición con el masculino, puede expresar un significado nuevo frente al masculino: la indeterminación, y ello simplemente con que en el contexto falten términos femeninos con los que concordar. Además, señala Mariner, el femenino resulta más adecuado para dejar las cosas en la imprecisión, pues el neutro, aunque hace referencia a lo conceptual, es concreto, como se ve en la oposición me lo pagarás vs. me las pagarás.

La propuesta de Mariner introduce el planteamiento de Delbecque. Para Delbecque (1997), la abundancia del femenino y su predominio sobre el masculino se debe al carácter marcado del femenino. Según Delbecque (1997: 217), para que una construcción sea considerada locución, es preciso que los rasgos del pronombre dependan del contexto: al tratarse del elemento no marcado, este constituye la expresión por defecto, de tal forma que abarcará todos los usos predictibles, que, en el caso que nos ocupa, sería que el clítico tomara su referencia a través de la concordancia del entorno sintáctico inmediato. Por el contrario, el elemento marcado quedará limitado a los usos menos previsibles, lo que permitirá destacar automáticamente ciertos usos $\mathrm{y}$, por ello, ser la tendencia dominante para la función de las locuciones. En el caso de la oposición masculino/femenino, está claro que el femenino se presenta como marcado, tanto formal como semánticamente, por eso que se preste con mayor facilidad a empleos locucionales. De igual forma, en la dualidad singular/plural, es claro que 
el elemento marcado es el plural. Así, en caso de no implicar pluralidad (por falta de correferencia en nuestro caso), la morfología plural será señal de alguna otra particularidad semántica. Todo ello se verá potenciado, evidentemente, en la combinación femenino y plural. En conclusión, pues, la flexión femenina, y más todavía la femenina plural, será una de las combinatorias morfológicas más favorables para la consolidación de una construcción como locución, pues será una marca no solo eficaz y económica, sino clara y escueta, de que el significado de la construcción es diferente del uso habitual de la lengua. De alguna forma, serían una manifestación del concepto de división de trabajo pragmático de Horn (1984: 22)2 incluido por Levinson en su principio M (2004: 214) ${ }^{3}$.

Señala Delbecque igualmente (1997: 217) que el clítico de complemento directo cumplimenta una posición funcional en la estructura argumental propiciada por el verbo, de forma que su presencia es esperada y no marcada, siendo su particularidad que no actualiza ningún referente nominal específico del entorno sintáctico inmediato. Sin embargo, debemos comentar que hay ocasiones en que eso no es así, por ejemplo, pirárselas es un verbo de desplazamiento intransitivo, lo cual es, en principio, incongruente con un clítico de complemento directo. Será, por tanto, una señal más para marcar el significado contextual de la construcción.

\subsection{Aspectos formales}

Albano \& Ghío (2013) y, especialmente, García Page (2010), se han ocupado de organizar las principales características formales de las locuciones con clítico femenino.

El primer y más sencillo esquema construccional es el de verbo transitivo + clítico: diñarla, palmarla, cascarla, etc. Este esquema también puede desarrollar otros esquemas más complejos: a) modificación del clítico por un predicativo: cantarlas

2 El uso de una expresión marcada (relativamente compleja o prolija) cuando una expresión no marcada alternativa es posible (más simple o de menos esfuerzo), tiende a interpretarse como suministrando un mensaje marcado (uno que la alternativa no marcada no podría haber dado).

3 Máxima del hablante: Indica una situación anormal y no estereotípica usando expresiones marcadas que contrastan con aquellas que se usarían para describir la correspondiente situación normal y estereotípica.

Corolario del receptor: Lo que se dice de un modo anormal indica una situación anormal, o los mensajes marcados indican situaciones marcadas, concretamente:

Donde $H$ ha dicho "p" con una expresión marcada M, y existe una expresión alternativa no marcada $E$ con la misma denotación $D$ que el hablante podría haber empleado en el mismo marco oracional; entonces, donde $E$ habría implicado-I el subgrupo estereotípico o más específico $d$ de $D$, la expresión marcada $M$ implicará el complemento de la denotación $d$, a saber đ de $D$. 
claras, hacerla buena, etc.; b) presencia de un complemento circunstancial o de régimen, con o sin predicativo: no tenerlas todas consigo, pagarla con alguien, etc.; c) modificación del clítico por un complemento prepositivo: llevar las de ganar, etc.; d) complementación por una relativa: estar a la que salta; e) combinación con estructura de infinitivo o gerundio: verlas venir, matarlas callando.

El segundo esquema construccional supone un verbo transitivo + clítico + complemento indirecto: pegársela, debérsela, jurársela, etc., siendo argumental el complemento indirecto y constituyendo el destinatario o meta de la acción referida. Una variante de este esquema es aquel en el que el clítico tiene un papel de tema y el sujeto es la causa del estado: sudársela, bufársela, etc.

El tercer esquema es el conformado por verbo pronominal + clítico: agenciárselas, ganársela, etc. El rasgo determinante en este tipo de construcciones es la presencia de un clítico de dativo concordado. Este esquema también puede desarrollar un subtipo como es el de la combinatoria con un complemento de régimen: entendérselas con, tenérselas con, etc.

El cuarto esquema es el de verbo intransitivo + clítico: pirárselas, guillárselas, etc., que es el esquema que acoge el objeto de nuestro estudio.

Creo que debemos entender como algo natural el hecho de que algunas locuciones puedan tener diversos significados según los contextos. Por ejemplo, clavársela a alguien, según el contexto en el que esté inserta la construcción, puede significar: 'herir, hacer daño', 'meter gol', 'perjudicar', 'copular'. De igual forma, puede haber marcas sintácticas que permitan diferenciar significados: cogerla alguien significa 'emborracharse', pero cogerla con alguien' significa 'convertir a esa persona en objeto de aversión'.

Al centrar nuestro trabajo en el español europeo, no hemos tratado muchas locuciones que quizás podrían enriquecer las características formales anteriores ${ }^{4}$. La riqueza expresiva de tales usos a uno y otro lado del Atlántico dan prueba de la vigencia del modelo construccional. Dicho modelo construccional no es exclusivo de la lengua española, sino que aparece en otras lenguas románicas 5 .

En definitiva, pues, nos encontramos con numerosas locuciones verbales que contienen un clítico de complemento directo, sea singular o plural, y dicho clítico carece de una referencia precisa o determinada, de forma que no se puede sustituir o ser reconstruido por ningún sintagma nominal previamente proferido. En algunos casos, puede parecer fácil sincrónicamente la reconstrucción de dicho clítico, como

$4 \quad$ Vid. estudios específicos como Orduña (2011), Guio \& Albano (2013) o Cordero \& Leoni (2017).

$5 \quad$ Vid., por ejemplo, García Benito (2009) para el portugués. 
cuando alude al órgano sexual masculino, lo cual nos conduce a su posible vinculación con el eufemismo ${ }^{6}$, pero en la mayoría de las ocasiones no se puede restituir con cierta garantía el sustantivo al que se refiere el pronombre, de ahí la necesidad de un estudio histórico para poder determinar la procedencia del mismo.

\subsection{Objetivos y propuesta}

En este trabajo vamos a analizar históricamente (a partir de los datos de los corpus CORDE y CREA) el caso de pirárselas, particularmente interesante por cuanto parece mostrar una extraña compatibilidad sintáctica del constituyente representado por el clítico, pues resulta muy raro considerar que un uso intransitivo verbal, indicando desplazamiento del sujeto, pueda combinarse con un clítico femenino plural que señala complemento directo: no parece haber ningún tipo de referencialidad anafórica posible para las. En nuestra propuesta vamos a demostrar que dicha relación anafórica existe y permitirá aclarar sin ambages el significado de la construcción. Dicho recorrido histórico nos obligará a estudiar también el caso de otras construcciones con significado similar, como tomarlas, afufarlas, apeldarlas, liarlas, volarlas, guillárselas y tocárselas.

El esquema de trabajo que vamos a desarrollar es el siguiente: en el punto 2 presentaremos brevemente los conceptos de subjetivación y analogía, que nos servirán como herramienta metodológica para explicar los procesos que han ocasionado la construcción pirárselas y afines. En el punto 3 haremos un desarrollo histórico de pirárselas así como del resto de locuciones con significado similar señaladas anteriormente. En el punto 4 sintetizaremos las conclusiones a las que hemos llegado.

Incluso aceptando que la generalidad de las construcciones con clítico femenino pudiera referir de forma 'poco cortés', considero que, de forma genérica, las locuciones verbales con clítico femenino no suponen ningún recurso eufemístico porque no existe intención eufemística alguna en su empleo. Seguimos la tradición de Casas (1986) al considerar la definición discursiva del eufemismo, de ahí que no sea posible decir que un sustituto sea eufemístico, sino que, en un contexto o situación determinada, tiene un uso eufemístico. Genéricamente podemos señalar que las locuciones verbales con clítico femenino no suponen usos eufemísticos, pues no 'dulcifican' absolutamente nada. Consideremos como prueba de ello que muchas de estas expresiones vendrán clasificadas por la RAE como 'vulgares', o 'coloquiales', queriendo reivindicar con ello que en modo alguno están utilizadas para 'suavizar socialmente' nada. 


\section{SUBJETIVACIÓN Y ANALOGÍA}

\subsection{Subjetivación}

La subjetividad es esencial en la significación de las locuciones con clítico femenino, por cuanto el significado subjetivo o expresivo supone el reconocimiento por parte del hablante de que algo se aparta de la norma, de lo esperable (la referencia sintáctica del clítico femenino), y provoca una manifestación explícita de que esto es así: el valor contextual o implícito del clítico femenino y del significado de la locución en su conjunto.

Traugott ha desarrollado una teoría del cambio semántico basada en la noción de subjetivación: un mecanismo semántico-pragmático a través del cual los significados cambian desde la descripción objetiva de la situación externa a la expresión de la perspectiva interna del hablante o la actitud sobre lo que se dice. Traugott distingue tres componentes distintos semántico-funcionales en la lengua en el nivel sincrónico (1982: 247-248): el proposicional (o ideacional), el textual y el expresivo (o interpersonal $)^{7}$. Mientras el componente proposicional tiene que ver con los recursos usados para la descripción del hecho de habla, el dominio textual afecta a aquellos rasgos que comunican significados que favorecen la cohesión. El componente expresivo comprende varios fenómenos de naturaleza subjetiva e intersubjetiva, que traslucen la evaluación y actitud del hablante hacia la proposición.

Esta hipótesis original de incremento diacrónico en la expresividad, o subjetividad, va siendo precisada poco a poco por Traugott. En 1989 reconoce que los cambios semánticos identificados en los procesos de gramaticalización no se limitan a la gramaticalización, sino que pertenecen a un conjunto de grandes tendencias en el cambio semántico que parecen sostener un amplio conjunto de fenómenos:

- Tendencia I (Traugott, 1989: 34): significados basados en la situación externa descrita > significados basados en la situación interna descrita (evaluativa/ perceptiva/cognitiva). Los cambios de este tipo incluyen cambios peyorativos, meliorativos, y un número de extensiones metafóricas desde dominios concretos a abstractos.

- Tendencia II (Traugott, 1989: 35): significados basados en la situación interna o externa descrita $>$ significados basados en la situación textual y metalingüística. Este cambio se muestra en el desarrollo de conectores que codifican

A partir de la distinción propuesta por Halliday \& Hasan (1976). 
cohesión textual, o en verbos de estados mentales que desarrollan valores metalingüísticos.

- Tendencia III (Traugott, 1989: 35): significados que tienden a ser incrementados a partir del estado de creencias o actitud subjetiva del hablante hacia la proposición. Ilustran esta tendencia cambios desde conectores temporales a concesivos, desde verbos de desplazamiento a marcadores de futuros, $\mathrm{y}$ desde modales deónticos a modales epistémicos, los cuales llegarán a ser denominados subjetivación.

Según Traugott \& Dasher (2002: 97), la tendencia III prevalece sobre las otras dos, de forma que la subjetivación puede considerarse como el principal tipo de cambio semántico. Para Traugott, la unidireccionalidad de los procesos de gramaticalización provoca una subjetivación creciente de la unidad o de la construcción lingüística, según la cual la unidad pierde contenido léxico pero consigue un mayor valor pragmático, es decir, el emisor es el origen del cambio lingüístico al subjetivar progresivamente sus mensajes. Así (Traugott \& König, 1991: 198), es posible observar una tendencia en los cambios que va desde significados basados en situaciones extralingüísticas identificables más o menos objetivamente, hacia significados basados en la actitud del hablante o en su creencia sobre lo que se dice. La implicación progresiva del sujeto de la enunciación en la descripción del objeto y del proceso produce una pragmatización del significado cada vez mayor, pues a través del uso repetido en contextos sintácticos locales, significados concretos, léxicos y objetivos llegan a realizar funciones progresivamente más abstractas, pragmáticas y basadas en el emisor (Traugott, 1996: 32), de forma que el cambio discursivo cristaliza en un cambio semántico y puede llegar a motivar el cambio sintáctico con el que culmina el proceso de gramaticalización. La subjetivación, en definitiva, no es otra cosa sino un cambio que va de lo que se dice a lo que se quiere decir.

La subjetivación, por tanto, puede ser entendida como un tipo de gramaticalización: el desarrollo de una expresión identificable gramaticalmente a partir de la creencia del hablante o la actitud del hablante sobre lo que se dice (Traugott, 1995: $32)^{8}$. Así pues, la subjetivación supone cómo ciertos elementos o construcciones

Algo diferente a la propuesta de subjetivación de Traugott es la propuesta de Langacker. El concepto
de subjetivación de Traugott corresponde a una visión pragmática de la subjetividad, y se basa en el
análisis histórico del cambio semántico en contexto. La definición de Langacker (1990, 1993, 1996,
1999) se centra en el papel de la construcción: la inclusión del hablante o conceptualizador en la
escena, como punto de referencia, hace dicha escena más subjetiva, siendo definida la subjetivación
como un proceso gradual de atenuación progresiva. La subjetividad viene referida no al significado 
convencionalizadas en la gramática de una lengua son resultado de un cambio lingüístico que incorpora a la gramática contenidos pragmáticos que codifican la perspectiva del hablante ante lo comunicado, como la relación con el interlocutor (lo que llamará intersubjetivación). Es decir, la subjetivación muestra cómo el significado pragmático puede llegar a gramaticalizarse y convertirse, por tanto, en una construcción convencional (Company 2004: 1): muchas veces las inferencias pragmáticas tienen que ver con valoraciones subjetivas (apreciaciones o valoraciones personales) que fuerzan al interlocutor a interpretar más de lo que realmente se dice; el interlocutor infiere adecuadamente lo que el hablante quería transmitir y supone que el matiz subjetivo inferido es un valor establecido de la forma o construcción emitida por el hablante. Tal asociación es repetida y generalizada hasta que el valor subjetivo se vuelve parte del significado convencional de la forma o construcción en cuestión (Company, 2003: 40). Es decir, se trata de un tipo de metonimia, resultado de la cual es un significado codificado nuevo y más subjetivo, que normalmente dará lugar a la polisemia (Traugott 2016: 379).

A pesar de su interés, la propuesta de la subjetivación no está exenta de problemas (De Smet \& Verstraete, 2006: 366): hay falta de criterios formales adecuados para detectar la subjetividad en un elemento particular, es decir, para medir cómo y por qué el elemento se relaciona con el hablante, y desde una perspectiva diacrónica hay a menudo confusión entre el papel del hablante en el proceso del cambio y la relación eventual del hablante con los nuevos sentidos que surgen como resultado de este proceso.

En ese sentido, es importante destacar la labor de Company, quien frente al análisis preponderante de la (inter)subjetivación desde un ángulo semántico-pragmático, se ha

inherente de un elemento lingüístico, sino a la manera en que cierto contenido conceptual es construido por el hablante. Langacker inicialmente caracterizó la subjetivación como la reordenación de alguna relación desde el eje objetivo al subjetivo (1990: 17), pero más tarde la redefinió como un proceso gradual de atenuación progresiva, en la que una relación objetiva desaparece, posibilitando una relación subjetiva que estaba originalmente inmanente en la objetiva. A diferencia de Traugott, Langacker no se preocupa por los detalles del proceso de cambio semántico, ni por los contextos específicos en que el cambio se produce en primer lugar, pues su interés no es desarrollar una teoría de la gramaticalización, sino una teoría de la gramática basada en una visión conceptualista de la semántica. Langacker utiliza la distinción objetivo/subjetivo como una forma adecuada de dar cuenta de las diferentes maneras en que una entidad puede ser construida dentro de la escena cognitiva. En la medida en que una entidad funciona como el sujeto o el objeto de una construcción, se dice que está construida subjetiva u objetivamente: está construida con subjetividad máxima cuando permanece «entre bastidores», implícita, intrínseca a los múltiples procesos de conceptualización sin ser su objetivo; y está construida con objetividad máxima cuando es patente y constituye un foco explícito de atención. 
preocupado estrechamente por examinar las consecuencias sintácticas de un proceso de (inter)subjetivación. Para Company (2004: 2), toda (inter)subjetivación supone una serie de restricciones en el comportamiento sintáctico de las formas que sufren ese cambio, consistentes en el debilitamiento e incluso cancelación de la capacidad sintáctica de los elementos implicados, es decir, hay un aislamiento sintáctico y cancelación de la sintaxis, consecuencia de la naturaleza del proceso de (inter)subjetivación.

Company sintetiza en 3 los efectos sintácticos del proceso de (inter)subjetivación. Estas características, de alguna manera, suponen la aplicación al español de rasgos como los reseñados por Ghesquière, Brems \& Van de Velde (2014: 139)9: a) atenuación, debilitamiento o pérdida de control del agente sobre el evento. Este debilitamiento del sujeto tiene como consecuencia una atenuación o debilitamiento de la estructura argumental de oración y, por tanto, de las relaciones entre los constituyentes del enunciado (inter)subjetivo, de forma que solo admite una interpretación global, y no a través del significado de sus constituyentes individuales. En ese significado global el hablante manifiesta su propio punto de vista sobre el evento. b) Ampliación del alcance de la predicación: las formas gramaticalizadas suelen situarse a la izquierda del enunciado, de forma que suelen iniciarlo, de manera que su significado incide sobre la oración en su conjunto, y no sobre algunos de los constituyentes del mismo. c) Fijación, aislamiento y autonomía predicativa. Es decir, el efecto sintáctico de este tipo de cambio es la reducción de la capacidad relacional de las formas sometidas a (inter)subjetivación. Ello puede conducir incluso al hecho de formar expresiones fijas.

Señala, además, Company un cuarto elemento semántico (Company 2004: 8): d) debilitamiento del significado referencial etimológico originario. Parece unánime la aceptación de que, para que las formas adquieran significados expresivos (inter) subjetivos, es requisito previo el vaciamiento en algún grado del significado referencial etimológico originario, lo que provoca nuevos significados más abstractos que entran en nuevos contextos, distintos de los originales.

Company (2004) se centra fundamentalmente en analizar el punto c) y en intentar dar una explicación al mismo. La hipótesis que fundamenta su trabajo es que «cuando las formas se recargan de significados subjetivos pragmáticos se desproveen de sintaxis, al punto de que muy frecuentemente cancelan la sintaxis normal que esas formas exhiben en su comportamiento objetivo. La subjetivación motiva aislamiento

Los elementos subjetivados no permiten la sustitución pronominal; no pueden ser incluidos en el alcance de la negación; resisten la focabilizadad, submodificación y gradabilidad; no pueden usarse predicativamente; es probable que diacrónicamente se somentan al movimiento a la izquierda y alcance de la expansión; resisten el control del agente; están prohibidos en ciertas cláusulas subordinadas; y son normalmente propios de una semántica no veritativo-condicional. 
sintáctico» (2004: 8). Dicho aislamiento se puede manifestar de diversas maneras: aislamiento mediante pausas, enunciado pleno autónomo (sus formas no pueden sustituirse, o parafrasearse, o tomar la complementación o modificación usual). La prescindibilidad de sintaxis en la (inter)subjetivación sería una manifestación más del efecto de 'reducción paralela' que sufren muchos cambios gramaticales, propuesto por Bybee, Perkins \& Pagliuca (1994: cap. 4).

Dentro de las conclusiones del análisis de Company, destaca la importancia del contexto: para que se dé un proceso de (inter)subjetivación es necesario que no haya un valor gramatical a priori, sino que el elemento/construcción adquiera su valor en el contexto, de forma que el hablante pueda manipular creativamente el contexto y desproveerlo de su significado originario para, así, enriquecerlo con sus propias valoraciones. Así pues, el análisis de Company (2004) confirma su hipótesis de que las construcciones que sufren un proceso de (inter)subjetivación rigidizan su sintaxis, pero, de alguna forma, este empobrecimiento sintáctico queda compensado con un fuerte enriquecimiento pragmático: la sintaxis es prescindible porque al hablante no le interesa la semántica descriptiva de la construcción, sino que le interesa aportar su propia visión respecto del evento. De ahí que, señala Company (2004: 23), mientras que la gramaticalización tradicional supone un cambio desde el léxico hacia la sintaxis, la (inter)subjetivación plantea un cambio desde la sintaxis hacia la pragmática.

\subsection{Analogía}

El concepto de analogía tiene gran tradición en la lingüística occidental ${ }^{10}$, especialmente en el campo de la morfología flexiva, y supone la influencia que unas formas pueden ejercer sobre otras de cara a la extensión de determinados patrones o esquemas o a la eliminación de ciertas irregularidades ${ }^{11}$ (Elvira 2010: 31), es decir, se trata de un proceso por el cual una forma lingüística llega a ser como otra debido a una asociación indirecta que está mediada por algún esquema o generalización de orden superior (Blevins \& Blevins 2009: 4). Pero la noción de analogía también tiene un gran predicamento en la ciencia cognitiva, al incidir por un lado en las capacidades asociativas de la mente humana a la hora de formar los conceptos y establecer relaciones entre ellos. La capacidad analógica de la mente humana consiste en la posibilidad de reconocer y procesar las similitudes entre las cosas y las realidades percibidas por los

10 Vid. Zamora Salamanca (1984) y Rainer (2013) al respecto.

11 El problema de lo que es regular e irregular se encuentra en el centro del debate que subyace a la relación entre reanálisis y analogía (Fischer 2007; De Smet 2009). 
sentidos (Elvira 2010: 32-33): apoyándose en la importancia que el uso y la frecuencia tienen en la organización de los esquemas lingüísticos, destaca la idea de que las capacidades lingüísticas descansan en habilidades cognitivas más generales, como la memoria y la capacidad asociativa de los hablantes. La analogía, por tanto, se refiere a un proceso cognitivo general que transfiere información específica o conocimiento desde un dominio a otro: conjuntos de percepciones, sean imágenes visuales, señales auditivas, experiencias, o sueños, son comparados, y son extraídas generalizaciones y conducidas a nuevos conjuntos (Blevins \& Blevins 2009: 2).

La analogía ha sido desconsiderada en los estudios formalistas sobre el lenguaje ${ }^{12}$. Los estudios formalistas de base generativa han tendido a pensar en las reglas como la base para las generalizaciones, reservando la analogía para esquemas restringidos léxicamente, y la analogía era desconsiderada en los estudios generativistas porque no podía ser reducida a reglas o restricciones (Fischer 2016: 240). Sin embargo, una regla puede ser entendida como una analogía muy genérica (Blevins \& Blevins 2009: 10), no hay necesidad de una diferencia cualitativa entre analogías generales y restringidas, y es plausible asumir que sus diferencias residen en la especificidad del esquema que debe ser igualado para sancionar una deducción analógica. Es más, en los últimos años, la analogía se considera uno de los principales mecanismos o principios que guían el aprendizaje y el cambio lingüístico (Mattiello 2017: 3). El uso de la analogía para explicar el cambio lingüístico también ha sido rechazado al señalar que es incapaz de predecir cuándo y de qué forma los cambios lingüísticos pueden suceder, pero este es un argumento poco convincente, por cuanto los cambios lingüísticos son impredecibles, y las explicaciones correspondientes son siempre posteriores: ninguna teoría puede predecir los cambios lingüísticos (Itkonen 2005: 75).

La extensión analógica no se basa simplemente en una comunidad formal (Elvira 1998: 151), sino que se puede ver reforzada por la presencia de rasgos semánticos o funcionales comunes entre los elementos que experimentan la influencia formal. En palabras de Itkonen (2005: 13), la analogía es relativa a un contexto de uso. Fischer (2010) va un paso más allá y señala que la analogía se basa tanto en la forma como en el significado, constituyendo un principio cognitivo fundamental que juega un papel primordial en la adquisición del lenguaje, y también en el cambio. Ya que la teoría de la gramaticalización constituye un modelo explicativo del cambio lingüístico, se debe concluir que la analogía debe jugar un papel importante en la gramaticalización. Pero la analogía no se restringe a la extensión analógica, es decir, un mecanismo

12 Chomsky (1989: 32) parece considerar la analogía como «simplemente un concepto inapropiado». Itkonen (2005: 67-76) debate críticamente las objeciones a la analogía en GU. 
formal que habitualmente se reconoce como uno de los factores que intervienen en la gramaticalización, la analogía también motiva el cambio lingüístico (Fischer 2010: 182). Por medio de la analogía podemos cambiar estructuras y los contenidos de paradigmas, pero es también la analogía la que ocasiona que podamos construir tipos abstractos o esquemas, es decir, la analogía puede afectar tanto a la forma como al significado, por tanto, el proceso analógico solo puede ser explicado desde las formas y los significados que las estructuras análogas tienen para los hablantes dentro de su sistema sincrónico de gramática y dentro de su situación comunicativa, pero es la analogía misma, junto con la frecuencia, la que ha ayudado a construir este sistema (Fischer 2008: 368).

Partiendo de la propuesta de Fischer, Traugott \& Trousdale (2013) han diferenciado entre el mecanismo de la analogía, que denominan analogización, y el pensamiento analógico, para evitar la ambigüedad entre el mecanismo del cambio y la motivación del mismo. El pensamiento analógico puede o no resultar en cambio, sin embargo, la analogización es un mecanismo de cambio que incide en similitudes que antes no existían. La analogización supone la asignación de un nuevo significado o forma, es decir, un cambio construccional, y por ello implica reanálisis. El pensamiento analógico es un importante factor en el incremento de la productividad o esquematicidad. Por medio de la analogía podemos cambiar construcciones, pero es también la analogía, como pensamiento analógico, la que ocasiona construir tipos o esquemas más abstractos, como principio cognitivo en la mente del hablante. La capacidad de combinar cosas y categorizar supone pensamiento analógico. El pensamiento analógico y el razonamiento preceden a muchos cambios, en tanto que supone el reconocimiento por parte del hablante de las similitudes entre dos construcciones. Es por ello por lo que hemos señalado que es una motivación para muchos cambios, pero no constituye cambio o innovación alguna, es una condición previa para el cambio. Se trata, en definitiva, de una distinción paralela a la establecida por Fertig (2013: 12) entre analogía en sentido general y analogía en sentido estricto.

Comenta Elvira (2010: 125) que el efecto de la analogía en la gramaticalización puede producirse, al menos, de dos maneras diferentes: puede afectar a rasgos del comportamiento del elemento que se gramaticaliza, y puede fomentar el incremento de la productividad del esquema en el que se ha producido la gramaticalización. Este es un interesante debate (Booij 2010: 89): saber si la formación de nuevos elementos puede considerarse analogía, o es resultado de la utilización de esquemas simbólicos que generalizan conjuntos de elementos. Ahora bien, los dos modelos no son excluyentes, pueden coexistir (Booij 2010: 91). Mattiello (2017: 64-74) distingue (en un recorrido gradual) entre analogía de superficie, es decir, la analogía en el sentido tradicional de 
mecanismo local, donde el modelo se restringe a un elemento concreto, con un alto grado de similitud entre los elementos afectados en la comparación analógica, y la productividad muy limitada del proceso, y analogía vía esquema, donde una serie de elementos comparten la misma formación, o un grupo de elementos comparten la misma base de formación; es más, la analogía puede ser el primer paso para el desarrollo de un esquema. Rainer (2013) resume adecuadamente el enfrentamiento entre la visión de la analogía según un modelo único y según una regla plenamente productiva, al presentarlos como dos extremos de un continuo gradual, lo cual no quiere decir, evidentemente, que todo pueda reducirse a analogía, pero sí nos parece muy importante (especialmente para los objetivos de nuestro trabajo: las construcciones con clítico femenino como contexto general de 'pirárselas') el reconocimiento de la productividad analógica, a través de modelos esquemáticos abstractos en distintos niveles.

\section{PIRÁRSELAS}

La locución pirárselas (RAE: loc. verb. coloq. pirarse) está vinculada, evidentemente con el verbo pirar: «1. intr. coloq. Hacer novillos, faltar a clase.2. prnl. coloq. Fugarse, irse. Manolo se piró de casa.» La RAE considera el verbo denominal, construido a partir de pira, del caló pira 'fuga, huida'. Sin embargo, Corominas \& Pascual (1984) entienden que el verbo está formado del gitano pirar 'andar, correr, pasear', siendo pira sustantivo derivado del verbo. La primera documentación que datan Corominas \& Pascual es de 1896, pirarse. Nosotros hemos documentado, sin embargo, un ejemplo 50 años antes:

y el hombre es castizo, siempre que corre se pira y se escapa, (CORDE, 1847 Estébanez Calderón, Serafín, Escenas andaluzas, bizarrías de la tierra, alardes de toros, ESPAÑA, Relato breve culto Alberto González Troyano, Cátedra, Madrid, 1985).

En cualquier caso, el verbo ha sido formado en el siglo XIX, y no es un verbo frecuente, tampoco en el CREA, pues sus usos son muy ocasionales ${ }^{13}$. La locución pirárselas es posterior, pues sus primeros usos atestiguados son del siglo $\mathrm{XX}^{14}$. Sin embargo, es importante señalar que los primeros ejemplos que encontramos no vienen referidos al valor de 'irse', sino al de 'morir', pues se trata de significados metafóricos del desplazamiento como muerte:

13 La RAE incorpora pirarse en sus ediciones de 1927 y 1950, y lo entiende como «vulgarismo», con el significado de 'irse, fugarse'. En la edición de 1970, y posteriores, recoge la forma pirar.

14 La RAE la incorpora al diccionario en la edición de 1970. 
agarró una pulmonía doble que de poco se las pira. (CORDE, 1917 Arniches, Carlos, Los ambiciosos [Del Madrid castizo. Sainetes], ESPAÑA, Breve, José Montero Padilla, Cátedra, Madrid, 1994).

¿Qué hacía usted? - ¡Me las piraba, amigo Muela, me las piraba! Si yo fuera el primer actor de una compañía de verso y me trajesen a mi teatro un bailarín de color, me daba un tiro, ¡vaya si me lo daba...! (CORDE, 1922 Insúa, Alberto, El negro que tenía el alma blanca, CUBA, Relato extenso novela..., Santiago Fortuño Llorens, Castalia, Madrid, 1998)

si no le agarra Liboria la de Villafranca se las pira del patatús, (CORDE, 1927 Noel, Eugenio Las siete cucas, ESPAÑA, Relato extenso novela..., José Esteban, Cátedra, Madrid, 1992).

No será hasta bien entrado el siglo XX cuando se acrediten los significados no metafóricos de desplazamiento, que son los que perduran hasta la actualidad, no habiendo constancia del significado metafórico de 'morir'15:

Oye, cuéntales a éstos cómo te las piraste sin pagar de Gijón. (CORDE, 1940, Zunzunegui, Juan, Antonio de El Chiplichandle. Acción picaresca, ESPAÑA, Relato extenso novela..., Studios, Madrid, 1940).

A lo mejor "nos las piramos" en avión a Bilbao... (CORDE, 1953, Borita Casas, Antoñita la fantástica y Titerris, ESPAÑA, Relato extenso novela ..., Gilsa, Madrid, 1953).

y se las piró a Santiago. (CORDE, 1958, Delibes, Miguel, Diario de un emigrante, ESPAÑA, Relato extenso novela..., Destino, Barcelona, 1958).

Las locuciones darse el piro o ir de pira son también posteriores a pirárselas, por lo que no parece que puedan haber influido en ella. La locución ir de pira (RAE: «1. loc. verb. En la jerga estudiantil, no entrar en la clase. 2. loc. verb. Ir de parranda, juerga o jarana») presenta algunas variantes: en el CORDE hemos encontrado 1 ejemplo con irse, 1 ejemplo con marcharse y 4 ejemplos con salir:

Conque entonce coge y se va de pira par palacio. (CORDE, 1920, Anónimo, Cuentos populares españoles, ESPAÑA, Relato breve tradicional, CSIC, Madrid, 1946).

15 Hay un par de ejemplos, pero tal y como vienen expresados dejan constancia precisamente del valor metafórico de su significado y señalan fundamentalmente desplazamiento:

El que muere se las pira. (CREA, 1975, Arrabal, Fernando, El Arquitecto y el Emperador de Asiria, ESPAÑA, Teatro, Taylor, Diana, Cátedra, Madrid, 1993).

El difunto ahuecó el ala, se las piró... (CREA, 1979, Romero Esteo, Miguel, El vodevil de la pálida, pálida, pálida, pálida rosa, ESPAÑA, Teatro Fundamentos, Madrid, 1979). 
y se marcha de pira ande stá su papá. (CORDE, 1920, Anónimo Cuentos populares españoles, ESPAÑA, Relato breve tradicional, CSIC, Madrid, 1946).

Y salió de pira tocando er tambó. (CORDE, 1920, Anónimo, Cuentos populares españoles, ESPAÑA, Relato breve tradicional, CSIC, Madrid, 1946).

Darse el piro ${ }^{16}$ se atestigua en la segunda mitad del XX, y si bien en el CORDE solo encontramos 3 ejemplos, en el CREA acreditamos 21 casos, lo que parece significar que es la construcción que ha pervivido (frente a ir de pira (y variantes) que no se atestigua en el CREA):

Sin la mujer se hace un poco cuesta arriba darse el piro. (CREA, 1962, Olmo, Lauro, La camisa, ESPAÑA, Drama, Ángel Berenguer, Cátedra, Madrid, 1988).

Y si me doy el piro de aquí es por arreglar las cosas. (CREA, 1962, Olmo, Lauro, La camisa, ESPAÑA, Drama, Ángel Berenguer, Cátedra, Madrid, 1988).

¿Alzar el telón y darse el piro? (CREA, 1963 - 1967, Olmo, Lauro, El cuarto poder, ESPAÑA, Drama, Ángel Berenguer, Cátedra, Madrid, 1988).

Así pues, la locución pirárselas está construida a partir del significado del verbo pirarse, con el que no presenta variación de significado. En cuanto a la presencia expresiva e intensificadora del clítico femenino plural, no hemos acreditado razón alguna para la misma. Por ello, vamos a continuar nuestro análisis con otras locuciones con el mismo significado hasta encontrar una explicación. El orden que utilizaremos será históricamente inverso.

3.1 Tocárselas. La RAE atestigua esta expresión: tocárselas alguien: «1. loc. verb. coloq. coger las de Villadiego». El significado de desplazamiento de la expresión puede venir dado a partir de los significados de tocar. La RAE da cuenta de un significado de desplazamiento de tocar: «20. intr. Llegar o arribar, solo de paso, a algún lugar» ${ }^{17}$. Este significado, quizás vinculado también con la idea de 'tocar tierra', es el que parece haber motivado la expresión. Aunque semánticamente podría haber una vinculación con la expresión tocar a rebato ${ }^{18}$, muy común desde el siglo XVI, no vemos acreditada relación posible alguna.

16 Según la RAE, piro es un sustantivo derivado de pirarse: «1. m. coloq. Acción y efecto de pirarse. Se dio el piro».

17 Este significado lo incorpora la RAE a su diccionario en la edición de 1803.

18 RAE: tocar a rebato: «1. loc. verb. Dar la señal de alarma ante cualquier peligro. 2. loc. verb. desus. Se empleaba para expresar el peligro de una incursión repentina del enemigo sobre el pueblo, al cual se avisaba tocando aprisa las campanas para que se pusiese en defensa». 
El principal problema de la locución tocárselas es que apenas hay ejemplos ${ }^{19}$. Solo he encontrado un ejemplo en el CORDE y la posibilidad de uno más en el CREA, si bien en este último no está claro su significado:

El cantor sin aguardar más, y considerándose desquitado, devolvió la guitarra al negro, saludó á todos y se las tocó para su pago; lo mismo hicieron á ese tiempo varios paisanos, pero la reunion no se deshizo. (CORDE, 1892, Fernández y Medina, B. Charamuscas, URUGUAY, Relato extenso novela..., Librería Nacional de A. Barreiro y Ramos, Montevideo, 1892).

cuando todavía se jugaba al diábolo, que es un cucurucho de goma que se lanza a las nubes, y si se las toca las hace llover, y el mar se crece y se mete en esos países, que se llaman así porque están más bajos que el mar (CREA, 1979, Luca de Tena, Torcuato, Los renglones torcidos de Dios, ESPAÑA, Novela, Planeta, Barcelona, 1994).

Así pues, son muy pocos los datos disponibles para ofrecer una explicación de la construcción. No obstante, todo parece indicar que la locución surge a partir del significado de desplazamiento del verbo tocar, no pudiendo dar cuenta todavía de la motivación del clítico femenino plural.

3.2 Guillárselas. La RAE atestigua esta locución: «1. loc. verb. coloq. pirárselas». Está construida a partir del verbo guillarse: «1. prnl. coloq. Irse o huirse». Según Corominas \& Pascual (1984), se trata de una voz jergal debida a un cruce de germanía guiñarse ('irse, huirse') con la familia del catalán esquitllar-se, castellano escullarse ('escullirse, 'escabullirse'). Guiñarse lo explican Corominas \& Pascual metonímicamente, a través de las señas que se hacen los malhechores para escapar cuando corren peligro. Corominas \& Pascual acreditan el verbo guillar en 1870, y la locución guiyárselas en 1882-3. En el CORDE no aparecen los ejemplos atestiguados por Corominas \& Pascual, pero los datos acreditados son muy parecidos, a pesar de ser muy pocos los ejemplos encontrados: el primer ejemplo de guillarse, en tanto 'irse', es de $1876^{20}$. Después encontramos un ejemplo más, pero con el significado de 'chiflarse' (1896). Ya no acreditamos más usos en el CORDE, y dos más en el CREA $^{21}$, lo que deja constancia de la poca frecuencia de su uso:

\footnotetext{
$19 \quad$ La RAE incluye la locución tocárselas uno en su edición de 1925.

20 La primera aparición del verbo en el diccionario de la RAE (siempre bajo la forma pronominal) es en la edición de 1899, y remite a guiñar en su última acepción ('irse, huirse').

${ }^{21}$ Los ejemplos en el CREA son de significados metafóricos derivados (RAE: «2. prnl. coloq. chiflarse (\| perder la energía de las facultades mentales). 3. prnl. coloq. Cuba. Simular desconocimiento de algo)», como en:
} 
los palatunós se guillaron (22) Marcharon. desmotados (CORDE, 1876 - 1880, Zugasti y Sáenz, Julián, El Bandolerismo. Estudio social y memorias históricas, ESPAÑA, Historiografía, Ediciones Albolafia, Excma. Diputación Provincial de Córdoba, Virgilio Márquez Editor, Córdoba, 1983).

los imbéciles tan pronto piensan en francés, como se guillan y se vuelven anglófilos... (CORDE, 1897, Pardo Bazán, Emilia, El niño de Guzmán, ESPAÑA, Relato extenso novela..., Biblioteca Virtual Miguel de Cervantes, Universidad de Alicante, Alicante, 2002).

Lo que sí encontramos de forma más habitual es el participio guillado/a con el significado de 'chiflado'22 (y ello también en el CREA ${ }^{23}$ ). Son 13 los ejemplos hallados:

y decían de él que estaba algo guillado y que había perdido la cabeza queriendo descubrir el movimiento continuo. (CORDE, 1884, Ortega Munilla, José, Cleopatra Pérez, CUBA, Relato extenso novela..., Juan Ignacio Ferreras, Cátedra, Madrid, 1993).

La locución guillárselas la acreditamos en 1883, aunque también es poco frecuente $^{24}$, pues solo aparecen 4 ejemplos en el CORDE, siendo el último de 1970, lo cual puede significar que su uso poco frecuente llega hasta la actualidad, a pesar de no encontrar ejemplos en el CREA.

Por de pronto, yo me las guillo. ¿Quiere usted algo para aquellos vericuetos? (CORDE, 1883, Pardo Bazán, Emilia, La Tribuna, ESPAÑA, Relato extenso novela..., Benito Varela Jácome, Cátedra, Madrid, 1995).

antes de entregarlo a la Inestal y en poco se las guilla... de miedo... (CORDE, 1927, Noel, Eugenio, Las siete cucas, ESPAÑA, Relato extenso novela..., José Esteban, Cátedra, Madrid, 1992).

Don Bruno, que era verdad, que se las ha guillado... (CORDE, 1927, Noel, Eugenio, Las siete cucas, ESPAÑA, Relato extenso novela..., José Esteban, Cátedra, Madrid, 1992).

Me doy por enterao, pero entérate tú también que el miércoles me las guillo. (CORDE, 1970, Díaz-Cañabate, Antonio, Paseíllo por el planeta de los toros, ESPAÑA, Deportes y juegos, Salvat-Alianza Editorial, Madrid, 1970).

Se creyó que me estaba guillando, que dormía recostado al cubo. (CORDE, 1981, Barnet, Miguel, Gallego, CUBA, Novela, Alfaguara, Madrid, 1981).

El sitio estaba como bocaelobo, como pa' guillarse. (CREA, 1993, Ramos Escobar, José Luis, El olor del popcorn, PUERTO RICO, Teatro Cultural, Puerto Rico, 1996).

22 Así como 5 ejemplos de guilladura (RAE: «1. f. coloq. Acción y efecto de guillarse (\| chiflarse)») en CORDE y 1 más en CREA.

23 Hay 5 ejemplos en el CREA.

$24 \quad$ La RAE la incorpora al diccionario en su edición de 1989. 
Así pues, la correlación de fechas da prueba de que la locución se construye a partir del significado de guillarse en tanto 'irse'. La presencia del clítico femenino plural sigue siendo todavía un interrogante.

3.3 Volarlas. La RAE no atestigua esta locución. No obstante, al ser el verbo volar un verbo de manera de desplazamiento, no resulta extraño su significado de 'huir'. De hecho, hay algunos significados de volar con los que tiene una gran relación: RAE: «4. intr. Caminar o ir con gran prisa y aceleración. Miró el reloj y salió volando. 5. intr. Dicho de una persona o de una cosa: Desaparecer rápida e inesperadamente». El problema es que solo encontramos un testimonio referido por Correas:

afufolas, apeldolas, liolas, bololas, tomolas, para dezir que uno huió i se fué. (CORDE, 1625, Correas, Gonzalo, Arte de la lengua española castellana, ESPAÑA, Lingüística, lenguaje, Emilio Alarcos García, CSIC, Madrid, 1954).

No sería de extrañar que se utilizara la expresión con el clítico femenino plural y el verbo volar, pero no hay datos en el CORDE, y los únicos testimonios, siempre con antecedente nominal para el clítico femenino, son de usos con los significados de 'hacer volar' 25 , 'salir volando' 26 , 'llevar volando' 27 o 'hacer explotar'28.

25 En el ejemplo:

porfías con él a volar más de estas dos perdices y de la manera que tengo dicho que las vueles (CORDE, 1565, Zúñiga y Sotomayor, Fadrique de, Libro de cetrería de caza de azor, ESPAÑA, Deportes y juegos, Dámaso Gutiérrez-Arrese, Bibliófilos españoles, Madrid, 1953).

26 Como se observa en:

Los de todo genero de bolateria lleuauan descubiertas cabeças, alas, y pies, y a no estar en las piguelas del pan, huuieran penetrado el ayre, aunque a muchas las bolaron (CORDE, 1623, Almansa y Mendoza, Andrés de, Relación del banquete ofrecido por el marqués de Astorga, ESPAÑA, Cartas y relaciones José Simón Díaz, Instituto de Estudios Madrileños, Madrid, 1982).

27 Véase:

Hubo en días pasados una tempestad tan grande, causada de una huracan tan furioso, que en Sevilla se llevaba las tejas de los tejados, y las volaba de una calle á otra. (CORDE, 1659 - 1664, Anónimo, Noticias de la Corte, ESPAÑA, Prensa Antonio Paz y Melia, Imprenta de M. Tello, Madrid, 1893).

28 En el ejemplo:

Pero para conseguir el intento dicho de allanar y romper las montañas, los hombres pláticos de nuestro tiempo, para evitar tanto gasto y fatiga como era contrastar a fuerça de braços con las peñas bivas y muy duras, han hallado el uso de las minas de pólvora para bolarlas (CORDE, 1592, Collado, Luis, Plática manual de artillería, ESPAÑA, Ejército y ciencia militar, Cristina Blas Nistal, CILUS, Salamanca, 2000). 
3.4 Liarlas. La RAE da a esta construcción dos valores, pareciendo vinculados los dos por relaciones metafóricas, en tanto que la muerte es un viaje: «l. loc. verb. coloq. Huir, escaparse con presteza. 2. loc. verb. coloq. morir (\| llegar al término de la vida)». Es muy difícil establecer una relación metafórica de los significados de la construcción con el verbo liar, de ahí que tendamos a pensar en algún tipo de metonimia como causa de la explicación. Corominas \& Pascual (1984) recogen la acepción 'liarlas', 'huir', en el siglo XVII, en Polo de Medina, y parecen (pero no lo dicen explícitamente) establecer una metonimia causa-consecuencia con la acepción de liar, en tanto 'atar y asegurar los fardos y cargas con lías', a través del ejemplo del Quijote liar las armas sobre Rocinante, acción que tiene como consecuencia la marcha. Sería una explicación similar a la dada en las construcciones liar el hatillo o liar el fardo que significan 'huir' (Iribarren, 1994: 120). Efectivamente es una posibilidad interesante; sin embargo, extraña un poco la escasa acreditación de ejemplos al respecto con liar. Igual de interesante puede ser la explicación metonímica a través de las construcciones liar el petate ${ }^{29}$ y liar los bártulos ${ }^{30}$ : Iribarren (1994: 39) señala que la vinculación de liar el petate con 'morir' viene motivada por la contracción nerviosa que suelen realizar muchos moribundos, que van recogiendo con la punta de los dedos la ropa o colcha de la cama (como si liaran el petate). Sin embargo, aun sin mencionarlo, deja abierta otra posibilidad explicativa, y es que, al significar 'petate' el lío de ropas y cama del marinero, pudiera aludir metonímicamente al 'viaje' o desplazamiento que se efectúa cada vez que se lía el petate. La relación con 'muerte' a través de la metáfora 'la muerte es un viaje' es obvia.

La construcción liar (o preparar) los bártulos es también muy atractiva. Bártulo era un famoso jurista medieval, cuyas obras, llamadas los bártulos eran comunes entre los estudiantes de los siglos XVI y XVII. Los estudiantes, al acabar las clases, arreglaban o liaban sus bártulos, pues se trataba de apuntes sujetos con una correa. De 'abandonar la clase' se puede pasar metafóricamente a 'irse', y de ahí, metafóricamente también, a 'morir'.Como hipótesis, creo que resultan muy interesantes todas, y no son excluyentes. En cualquier caso, confirman la necesidad de una metonimia para explicar el valor de desplazamiento en el verbo liar. Ahora bien, las propuestas en sí tienen algunos problemas: los ejemplos con liar las armas son escasos, liar el petate

29 RAE: «liar alguien el petate: 1. loc. verb. coloq. Mudar de vivienda, especialmente cuando es despedido. 2. loc. verb. coloq. morir (\| llegar al término de la vida)».

30 RAE: «coger, o liar, los, mis, tus, etc., bártulos: 1. locs. verbs. coloqs. U. para intensificar la precipitación o el enfado que acompañan a la decisión de irse». 
aparece en 1870, con el significado de 'irse'31, liar los bártulos lo hace en 1872, con el significado de 'morir' 32 , y algo más tarde con el de 'irse'. En el siglo XVII no hay testimonios con liar el fardo, aunque sí con desliar ${ }^{33}$, y no es una construcción que se acredite más tarde. Liar el hatillo también es algo excepcional, aunque acreditamos un ejemplo vinculado en $1599^{34}$. Así pues, parece poco probable que las construcciones anteriores motivaran los significados de liarlas, pues no hay una relación directa con liar. También existe la posibilidad de que el significado de la construcción liarlas se crease independientemente del verbo, y que se formara directamente a partir de lía, o, mejor, lío, que sí era muy común vinculado con escenas como las anteriormente señaladas. En conclusión, el significado de la construcción liarlas como 'irse' ha debido de surgir probablemente por algún tipo de metonimia causa-consecuencia relativo a algún lío previo a un desplazamiento. Desde el desplazamiento, se puede llegar metafóricamente al significado de muerte.

31 En el ejemplo:

verán ustedes lo que tardo yo en liar el petate y en buscar, más que de prisa, una guarida (CORDE, 1870, Pereda, José María de, El peor bicho [Esbozos y rasguños], ESPAÑA, Relato breve culto Imprenta de M. Tello, Madrid, 1881).

No obstante, hemos encontrado un ejemplo previo con lio:

halló un lío de petate, que es como la que nosotros llamamos estera (CORDE, 1560, Cervantes de Salazar, Francisco, Crónica de la Nueva España, ESPAÑA, Historiografía Manuel Magallón, Atlas, Madrid, 1971).

32 Como se observa en los siguientes fragmentos:

Pero lo que sí es cosa averiguada es que lió los bártulos, pues no era justo que quedase sobre la tierra para semilla de pícaros. (CORDE, 1872, Palma, Ricardo, Tradiciones peruanas, primera serie, PERÚ, Otros, Biblioteca Virtual Miguel de Cervantes, Universidad de Alicante, Alicante, 2003). decidiose el señor obispo a liar los bártulos y volver a España (CORDE, 1883, Palma, Ricardo, Tradiciones peruanas, sexta serie, PERÚ, Otros, Biblioteca Virtual Miguel de Cervantes, Universidad de Alicante, Alicante, 2003).

33 Véanse:

Quiso una noche desliar el fardo de sus habilidades (CORDE, 1631, Castillo Solórzano, Alonso de, Las harpias en Madrid, ESPAÑA, Relato extenso novela..., Pablo Jauralde, Castalia, Madrid, 1985).

y en ocasiones como ésta desliaba el fardo desta mercadería (CORDE, 1642, Castillo Solórzano, Alonso de, La garduña de Sevilla, ESPAÑA, Relato extenso novela..., Federico Ruiz Morcuende, Espasa Calpe, Madrid, 1941).

34 Es el siguiente:

Llevaba liado su hatillo (CORDE, 1599, Alemán, Mateo, Primera parte de Guzmán de Alfarache, ESPAÑA, Relato extenso novela..., José María Micó, Cátedra, Madrid, 1992). 
La construcción liarlas con el significado de 'desplazamiento' tiene muy pocos ejemplos ${ }^{35}$. De hecho, solo hemos encontrado ejemplos en el siglo XVII (como señalaban Corominas \& Pascual) y en la primera mitad del XIX, en este último caso bajo la forma liárselas:

Ya que liarlas no puedo, / porque brota la campaña / tantos galgos, esta hazaña / puede asegurar mi miedo, / pues, entre ellos disfrazado, / tendré la vida segura / sin seguir yo la locura /de embestir a vn campo armado. (CORDE, 1624, Vergara, Hipólito de, La Virgen de los Reyes, ESPAÑA, comedia, Luis Iscla Rovira, CSIC, Madrid, 1975).

Ella, viendo el negocio mal parado, / las lio (como dicen los vulgares), / sin esperar a dares ni tomares; / pies puso en polvorosa (CORDE, 1630 - 1655, Polo de Medina, Salvador Jacinto, Poesía, ESPAÑA, individual, Francisco J. Díez de Revenga, Cátedra, Madrid, 1987).

Mas el hombre se las había liado; porque así que vio y oyó nombrar a Pedro Saputo se dio por perdido, y se escurrió y puso pies en polvorosa (CORDE, 1844, Foz, Braulio, Vida de Pedro Saputo, ESPAÑA, Relato extenso novela..., Francisco Ynduráin; Domingo Ynduráin, Cátedra, Madrid, 1986).

Así pues, la construcción liarlas con el significado de 'huir' es muy poco frecuente $^{36}$. Teniendo en cuenta precisamente esa poca frecuencia de uso, no debe extrañar la presencia de un uso de liar con el mismo significado de 'huir', lo que supondría, entonces, que la construcción surge a partir del significado verbal de liar. La forma de llegar al significado 'huir' desde liar tendrá que ser, seguramente, por las vinculaciones metonímicas con lío señaladas más arriba:

Mas desde a un rato mandó Gonzalo Pizarro prender a todos aquellos que se habían liado desde el pueblo de Jaxaguana y se habían venido al visorrey, como atrás queda dicho. (CORDE, 1549 - 1603, Gutiérrez de Santa Clara, Pedro, Quinquenarios o Historia de las guerras civiles del Perú, ESPAÑA, Historiografía, Ediciones Atlas, Madrid, 1963).

La presencia del clítico intensificador femenino plural solo parece justificada por analogía con las construcciones similares.

$35 \quad$ Además de la explicación proporcionada por Correas para las locuciones:

afufolas, apeldolas, liolas, bololas, tomolas, para dezir que uno huió i se fué. (CORDE, 1625, Correas, Gonzalo, Arte de la lengua española castellana, ESPAÑA, Lingüística, lenguaje, Emilio Alarcos García, CSIC, Madrid, 1954).

36 La RAE la incorpora en su primer diccionario (1734): «Phrase vulgar, con que se dá à entender que uno se huyó oculta y escondidamente». 
En el siglo XIX acreditamos la expresión liarlas con el significado de 'morir', alternando, además, con la forma liárselas ${ }^{37}$. Se trata de una construcción bastante común, que llega hasta principios del siglo XX. Independientemente de la posibilidad señalada por Iribarren de entender liar el petate como 'morir' a partir de la acción con las manos de los muertos, y teniendo en cuenta que la expresión liár(se) las es anterior a liar el petate, parece lógico pensar que el significado de la construcción surgiera como evolución del significado de liarlas en tanto 'huir', a partir de la metáfora 'la muerte es un desplazamiento':

¡Me han herido! TABERNERO ¡En mi casa! EL CURA Las lió. (Tira la guitarra y sale a escape.) (CORDE, 1840 - 1841, Espronceda, José de, El diablo mundo, ESPAÑA, Épico, Robert Marrast, Castalia, Madrid, 1993).

¡Ay! ¡Capuro, Sento mío! / ¡Caflición! ¡Ay! ¡Yo me muero! / No lo dudes, yo las lío... (CORDE, 1847, Azcona, Agustín, El sacristán de San Lorenzo: zarzuela en tres cuadros, ESPAÑA, drama musical, Biblioteca virtual Miguel de Cervantes, Universidad de Alicante, Alicante, 2003).

El médico, al verle así, no se anduvo en chiquitas, y de buenas a primeras le dijo que se preparase en toda regla, porque se las liaba. (CORDE, 1871, Pereda, José María de, Tipos y paisajes, ESPAÑA, Relato breve culto, Salvador García Castañeda, Ediciones Tantín, Santander, 1989).

Y si no acudo a tiempo y entramos en razón me las lío al otro mundo. (CORDE, 1914, Unamuno, Miguel de, Niebla, ESPAÑA, Relato extenso novela..., Armando F. Zubizarreta, Castalia, Madrid, 1995).

Así pues, la construcción liár(se)las surge a partir de los significados del verbo liar. La manera de vincular el significado de liar, en tanto 'atar', con liar en tanto 'huir', parece probable que se debiera a alguna metonimia causa-consecuencia a partir de lío ('porción de ropa o de otras cosas atadas') que se utilizaba en los desplazamientos. Sin embargo, liár(se)las con valor de desplazamiento es muy poco usado, siendo mucho más común su empleo como viaje al más allá. La expresividad intensificadora del clítico femenino plural sigue sin resolverse.

3.5 Apeldarlas. La RAE no recoge esta locución; sin embargo, la hemos visto acreditada anteriormente por Correas con el significado de 'huir'. Corominas \& Pascual (1984) consideran que el verbo apeldar (RAE: «1. intr. coloq. p. us. Escapar, huir») es una variante semiculta del latín APPELLARE 'dirigir la apalabra', 'apelar', 'llamar

$37 \quad$ La RAE la incorpora a su diccionario en la edición de 1803: «f. met. y fam. Lo mismo que morirse». 
(a alguien)'; el verbo romance era de empleo muy frecuente en los siglos XV-XVII con el sentido de 'escapar, huir', entendido como una abreviación de apeldar a la fuga; de donde también surgen apelde 'toque de llamada' y el antiguo apeldación.

El verbo apeldar tiene testimonios, aunque pocos, desde principios del siglo XV hasta la primera mitad del XVII, y en ellos alternan la variante con clítico concordado y sin él, si bien parece algo más habitual sin clítico ${ }^{38}$. La locución apeldarlas solo se documenta en el CORDE en el siglo XVII, si bien ya Correas la atestigua, lo que puede ser prueba de su uso habitual en la época ${ }^{39}$ :

mas yo, que aún tenía en la memoria la vereda del postiguillo, apeldélas hacia allá velozmente. (CORDE, 1617, Suárez de Figueroa, Cristóbal, El pasajero, ESPAÑA, Relato extenso novela..., M $M^{\text {a }}$ Isabel López Bascuñana, Promoción y Publicaciones Universitarias, Barcelona, 1988).

Apeldólas. Por: fuese huiendo. (CORDE, 1627, Correas, Gonzalo, Vocabulario de refranes y frases proverbiales, ESPAÑA, Paremiología, Louis Combet, Institut d'Études Ibériques et Ibéro-Américaines de l'Université de Bordeaux, Burdeos, 1967).

De la querella se aparta / sin duda. Yo las apeldo: libreme Dios de villanos, / que las bacas son buñuelos. (CORDE, 1672, Vélez de Guevara, Juan, Los celos hacen estrellas, ESPAÑA, drama musical, John Varey y N. D. Shergold, Tamesis, London, 1970).

Así pues, se trata también de una locución con poca vitalidad, al estar solo documentada en el XVII ligada al verbo apeldar, que también deja de documentarse en el siglo XVII, pese a contar con dos siglos más de documentación anterior en el CORDE. Teniendo en cuenta que el verbo significaba 'huir', la presencia del clítico femenino sigue sin explicación.

3.6 Afufarlas. La RAE incluye como desusada esta locución: «1. loc. verb. coloq. desus. Huir, desaparecer». El verbo también significa 'huir': «1. intr. coloq. desus. huir (\| alejarse deprisa). Era u. t. c. prnl.». Corominas \& Pascual (1984) explican la etimología de este verbo como una forma reduplicada creada con carácter expresivo a base del antiguo fuir. Y señalan que no creen que provenga de fufar, en tanto 'bufar el gato'. Sin embargo, la RAE mantiene esa apuesta, a partir de lo que sería una

38 Covarrubias incluye apeldar, definido como «huir, escapándose, por no ser detenido, o preso». La RAE lo incorpora también a su edición de 1726, y señala el uso del verbo como «jocoso».

39 La RAE incorpora en la entrada de apeldar, en la edición de 1770, lo siguiente: «Úsase ordinariamente con el pronombre las, y vale lo mismo que afufarlas». A partir de la edición de 1803 desaparece la parte final de la explicación («y vale lo mismo que afufarlas»), y permanece en los distintos diccionarios de la RAE desde entonces, incluida la edición de 1992. 
metonimia por el comportamiento del gato, en tanto que «hace fu, y desaparece». Efectivamente el verbo es poco usado ${ }^{40}$, pues acreditamos ejemplos a partir del siglo XVI y, a partir de finales del siglo XIX, no se registran más ejemplos en el CORDE ${ }^{41}$. El verbo parece usarse indistintamente con clítico de dativo concordado y sin clítico, si bien la primera variante ofrece el doble de ejemplos que la segunda. También hay testimonios de las locuciones tomar las afufas y estar sobre las afufas con el significado de 'huir' 42 . Asimismo documenta el CORDE otros significados relacionados con 'huir', como 'desaparecer'43, 'matar'44 o 'escapar'45.

Los primeros testimonios de la locución, que incluyen las citas de Correas al respecto, son algo posteriores al uso del verbo: finales del XVI. Los últimos testimonios son también de finales del XIX, igual que el verbo, lo que parece dar cuenta de la suerte de verbo y locución:

tomé las de Villadiego. Afufélas, que una posta no me alcanzara. (CORDE, 1599, Alemán, Mateo, Primera parte de Guzmán de Alfarache, ESPAÑA, Relato extenso novela..., José María Micó, Cátedra, Madrid, 1992).

40 La RAE incorpora en su primera edición de 1726 las voces afufar y afufarse y les asigna califica la marca de «vulgar y jocosa». También incorpora afufolas, o afufelas como locución.

41 Hay un ejemplo de Cortázar en 1963, pero dado el contexto en que se sitúa, bien podría tratarse de un ejemplo desusado; ello invita a no considerar que su uso llega hasta el siglo XX:

Oh emperatriz de los farmacéuticos, ten piedad de los afofados, los afrontilados, los agalbanados y los aforados que se afufan. (CORDE, 1963, Cortázar, Julio, Rayuela, ARGENTINA, Relato extenso novela... Julio Ortega; Saúl Yurkievich, Archivos, Madrid, 1991).

42 Como los siguientes:

yo os haré que toméis, mal de vuestro grado, las afufas. (CORDE, 1545 - 1565, Rueda, Lope de, Auto de los desposorios de Moisén, ESPAÑA, religioso, Real Academia Española, Madrid, 1908). y estaba sobre las afufas (CORDE, 1626, Quevedo y Villegas, Francisco de, Cuento de cuentos, ESPAÑA, Relato breve culto, Celsa Carmen García Valdés, Cátedra, Madrid, 1993).

43 Véase:

y viendo afufarse la casa de su vecino (CORDE, 1635, Quevedo y Villegas, Francisco de, La hora de todos y la Fortuna con seso, ESPAÑA, Relato extenso novela..., Luisa López-Grigera, Castalia, Madrid, 1975).

44 Como en:

porque le afufé la vida al zaino de Santo Horcaz. (CORDE, 1610 - a 1645, Quevedo y Villegas, Francisco de, Jácaras, ESPAÑA, Épico José Manuel Blecua, Castalia, Madrid, 1971).

45 Véase:

el forastero se le afufó de su poder (CORDE, 1637, Castillo Solórzano, Alonso de, Aventuras del Bachiller Trapaza, ESPAÑA, Relato extenso novela..., Jacques Joset, Cátedra, Madrid, 1986). 
afufolas, apeldolas, apeldolas, liolas, bololas, tomolas, para dezir que uno huió i se fué. (CORDE, 1625, Correas, Gonzalo, Arte de la lengua española castellana, ESPAÑA, Lingüística, lenguaje, Emilio Alarcos García, CSIC, Madrid, 1954).

Afufólas. Esto es: huió, akoxióse. «Afufarlas» es: huir. (CORDE, 1627, Correas, Gonzalo, Vocabulario de refranes y frases proverbiales, ESPAÑA, Paremiología, Louis Combet, Institut d'Études Ibériques et Ibéro-Américaines de l'Université de Bordeaux, Burdeos, 1967).

tengo ya pasaporte y recomendaciones del Rey para afufarlas a Francia a principios de Mayo, (CORDE, 1792, Fernández de Moratín, Leandro, Cartas de 1792 [Epistolario], ESPAÑA, Cartas y relaciones, René Andioc, Castalia, Madrid, 1973).

y en tanto que las afufaba, iba diciendo: (CORDE, 1880-1882, Montalvo, Juan, Las catilinarias, ECUADOR, Política y gobierno, Ayacucho, Caracas, 1985).

Así pues, estamos ante una locución desusada, que aparece documentada a finales del XVI y principios del XVII, algo después de la aparición del verbo, y que debió de ser común en la época, por el testimonio de Correas. La desaparición del uso del verbo parece que llevó aparejada también la desaparición de la locución, a finales del siglo XIX. El clítico femenino plural no tiene referencia, semántica o sintáctica, con ningún sintagma nominal, y seguimos sin encontrar una motivación histórica para el mismo.

3.7 Tomarlas. La RAE no recoge la locución. Ahora bien, sí la recoge Correas, como dijimos anteriormente, y, además explica su origen, tomar las calzas de Villadiego, si bien Correas creía que era anterior tomarlas a tomar las calzas de Villadiego. Sin embargo, hay ejemplos de tomar las calzas de Villadiego desde finales del siglo XV, mientras que los ejemplos con tomarlas son pocos, y limitados a los siglos XVI y XVII en los documentos del CORDE:

afufolas, apeldolas, liolas, bololas, tomolas, para dezir que uno huió i se fué. Esta postrera parte tomolas á crezido, i dizen tomó las de Villadiego por henchir mas el dicho, i porque corre bien la palavra Villadiego, i dexando el las dizen tomó calzas de Villadiego para dezir que huió i se fué de lixero. I no siento ni creo que tiene otra istoria, como diremos mas largo en los rrefranes. (CORDE, 1625, Correas, Gonzalo, Arte de la lengua española castellana, ESPAÑA, Lingüística, lenguaje, Emilio Alarcos García, CSIC, Madrid, 1954).

Fuera de la expresión tomar las calzas de Villadiego no hay ninguna relación entre el verbo tomar y la expresión del desplazamiento. De ahí que esté clara la relación entre las dos expresiones. Solo hemos atestiguado 4 ejemplos de la locución en el CORDE: 
Tirá, villanos descomedidos. ¿Y delante de mí semejante villanía y descomedimiento? Tirá afuera y no me volváis más á aqueste pozo si no queréis morir por ello.

bobo

Ansí; déles vuesa merced á los hi de ruines. Mas ¡qué presto las tomaron! (Echa Moisén á los villanos del pozo.) (CORDE, 1545-1565, Rueda, Lope de, Auto de los desposorios de Moisén, ESPAÑA, religioso, Real Academia Española, Madrid, 1908)

getrona

Mi señor, Dios te acompañe.

moisén

Y vaya en vuestra compañía.

bobo Adiós, adiós, señor, que las tomamos. (CORDE, 1545-1565, Rueda, Lope de, Auto de los desposorios de Moisén, ESPAÑA, religioso, Real Academia Española, Madrid, 1908).

Vanse Teodoro y Leonardo / LEANDRO ¿Royó el cabestro Teodoro? / JULIO Un amigo le llamó. / ARTANDRO En efeto, las tomó; / no tiene más ley que un moro. (CORDE, 1598, Vega Carpio, Lope de, La bella malmaridada o la cortesana, ESPAÑA, comedia, Enric Querol, Edición electrónica, S.L., 1999).

El segundo es el rufián por cuya cuenta corre que, así como se acaba el juego, se agarre de las barajas y las tome, para que no vayan a manos ajenas y se conozca la flor; (CORDE, 1611, Quevedo y Villegas, Francisco de, Vida de la corte y Capitulaciones matrimoniales, ESPAÑA, Relato breve culto, Celsa Carmen García Valdés, Cátedra, Madrid, 1993).

Villadiego: Viejecito, / yo soy ese Villadiego. / En mis calzas, ¿qué habéis visto / para decir que las toman / los que huyen? Antes son grillos / unas calzas atacadas, / y para ir su camino, / no tomallas, qu'el soltallas / les fuera mejor adbitrio. (CORDE, 1620, Quevedo y Villegas, Francisco de, Entremés de los refranes del viejo celoso, ESPAÑA, profano, José Manuel Blecua, Castalia, Madrid, 1981).

Así pues, como testimonian los ejemplos de Quevedo y Correas, parece que siempre estuvo presente la relación entre tomarlas y tomar las calzas de Villadiego, por lo que el clítico femenino plural se entiende siempre en esa relación semántica, de ahí, igualmente, el valor de desplazamiento que adoptan los distintos verbos al tomarlo.

3.8 Tomar las de Villadiego. RAE: «coger, o tomar, las de Villadiego: 1. locs. verbs. coloqs. Ausentarse impensadamente, de ordinario por huir de un riesgo o compromiso». Se trata de una de las expresiones más profusamente comentada por Iribarren (1994: 96-98). El sustantivo al que alude el dicho, a pesar de algunas explicaciones a partir de alpargatas o alforjas, es calzas. Ello, como recoge Iribarren, es algo atestiguado desde la primera aparición del término y repetido en los primeros usos: 
Apercíbete, a la primera voz que oyeres, tomar calzas de Villadiego. (CORDE, 14991502, Rojas, Fernando de, La Celestina. Tragicomedia de Calisto y Melibea, ESPAÑA, Otros, Francisco J. Lobera; Guillermo Serés; Paloma Díaz-Mas; Carlos Mota; Íñigo Ruiz Arzálluz; Francisco Rico, Crítica, Barcelona, 2000).

¡Maldito sea hombre tan fanfarrón! y si viene a mano el primero que tome calças de Villadiego será él. (CORDE, 1534 Silva, Feliciano de, Segunda Celestina, ESPAÑA, Relato extenso diálogo y..., Consolación Baranda, Cátedra, Madrid, 1988)

Porque el hombre bien armado / vive sin desasosiego, / y aún para estar más guardado / diz que andáis siempre calçado / de calças de Villadiego. (CORDE, 1540-1579, Horozco, Sebastián de, Cancionero, ESPAÑA, en obras colectivas, Jack Weiner, Herbert Lang, Frankfurt, 1975).

y el toro acudió por donde el Rey venía, de cuyo espanto los galanes desampararon al Rey y á las damas, y tomaron calças de Villadiego (CORDE, 1545, Anónimo, Sermón de Aljubarrota, con las glosas de D. Diego Hurtado de, ESPAÑA, Relato breve culto, Antonio Paz y Melia, M. Tello, Madrid, 1890).

Iribarren recoge distintas motivaciones para la expresión, siendo la más plausible la basada en el privilegio que el rey Fernando III, el Santo, concedió a los judíos del pueblo burgalés de Villadiego, prohibiendo que se les prendiese, y señalando penas para los que les hicieran daño. Así, en la época de mayor persecución, los judíos principalmente de Burgos y Toledo, consideraron Villadiego como una ciudad refugio, y hasta allí se marchaban al menor síntoma de persecución. Pero ello entrañaba la obligación de llevar un distintivo especial, para que se les pudiera reconocer que estaban bajo la protección del Rey y que nadie los pudiera prender. Este distintivo eran las calzas amarillas que debían usar en adelante en el nuevo lugar de acogida. Así pues, la alusión a las calzas de Villadiego viene a señalar el distintivo de quienes habían huido de su lugar de origen (habiendo tomado asilo en Villadiego), con lo cual la motivación metonímica entre las (calzas) de Villadiego y 'huir' queda explicada. Lo común de la expresión ocasiona que ya en la segunda mitad del XVI alterne la expresión completa tomar las calzas de Villadiego con tomar las de Villadiego; en el siglo XVII era más común la expresión sin sustantivo que con él, hasta el punto de que no disponemos de testimonios con sustantivo posteriores a Correas $(1627)^{46}$.

mas tengo para mí que los caudillos / fueron en la huída los primeros, / y viendo que faltavan ellos, / luego también tomaron las de Villadiego. (CORDE, 1586-1587,

46 Encontramos un ejemplo en el siglo XIX, pero entiendo que es debido al estilo artificioso del autor: tomástedes calzas de Villadiego e corristeis a puto el postre. (CORDE, 1847, Estébanez Calderón, Serafín, Escenas andaluzas, bizarrías de la tierra, alardes de toros, ESPAÑA, Relato breve culto, Alberto González Troyano, Cátedra, Madrid, 1985). 
Castellanos, Juan de, Discurso del Capitán Francisco Draque, COLOMBIA, Épico, Ángel González Palencia, Instituto de Valencia de Don Juan, Madrid, 1921).

Unos dejan allí las calzas luego, / Y otros tomaron las de Villadiego. (CORDE, 1589, Castellanos, Juan de, Elegías de varones ilustres de Indias, COLOMBIA, Épico, Buenaventura Carlos Aribau, Ribadeneira, Madrid, 1847).

La construcción con el verbo coger es muy poco habitual. Solo hemos encontrado dos ejemplos en el CORDE:

según él puso los pies en polvorosa y cogió las de Villadiego, no lleva pergenio de volver por él jamás. (CORDE, 1605, Cervantes Saavedra, Miguel de, El ingenioso hidalgo don Quijote de la Mancha, ESPAÑA, Relato extenso novela..., Francisco Rico, Instituto Cervantes-Crítica, Barcelona, 1998).

coged las de Villariego, / y para vuestro camino / os daré limosna luego (CORDE, 1617, Valladares de Valdelomar, Juan, Caballero venturoso, ESPAÑA, Relato extenso novela..., Adolfo Bonilla y San Martín y Manuel Serrano y Sanz, Impr. Rodríguez Serra, Madrid, 1902).

La expresión se conserva desde entonces hasta la actualidad, como queda demostrado por la abundante documentación de los corpus (alrededor de 105 ejemplos en el CORDE y 32 en el CREA):

y, sin decir ¡agua va!, toman las de Villadiego. (CORDE, 1650-1660, Conde de Rebolledo (Bernardino de), Ocios, ESPAÑA, individual, Rafael González Cañal, Ediciones de la Universidad de Castilla-La Mancha, Cuenca, 1997).

Con esto partí más alegre y confiado, tomando las de villadiego, pues en ruedas ni a caballo no había que pensar (CORDE, 1786, Montengón, Pedro, Eusebio, ESPAÑA, Relato extenso novela..., Fernando García Lara, Cátedra, Madrid, 1998).

pero se levantó un día de buen humor, y tomó las de Villadiego, con un francés, que pasaba a la Argelia. (CORDE, 1855, Castelar, Emilio, Ernesto: novela original de costumbres, ESPAÑA, Relato extenso novela..., Universidad de Alicante, Alicante, 2003).

se levantó de sus sillones y tomó las de Villadiego renunciando pávidamente a lo que viniera después. (CORDE, 1948, González Anaya, Salvador, Los costumbristas malagueños, ESPAÑA, Oratoria y discurso, RAE, Málaga, 1948).

Poco le faltó al cellista y director para tomar las de Villadiego. (CREA, 2003, PRENSA, El Cultural, 21/11/2003: LA PAPELERA DE JUAN PALOMO, ESPAÑA, Arte y cultura en general, Unidad Editorial, Madrid, 2003). 
Así pues, el clítico femenino de pirárselas tiene una explicación: la locución tomar las calzas de Villadiego. En el origen, el clítico sí cumplía la función de complemento directo y tenía un antecedente. La gramaticalización de la construcción en la forma tomarlas, con el significado de desplazamiento, como un proceso de subjetivación, pudo motivar la analogización de la construcción con clítico femenino plural a otros verbos con significado de desplazamiento. El carácter marcado socialmente de las construcciones quizás pudo contribuir a acotar el ámbito de uso de los mismos. En la tabla 1 está resumida la datación de las distintas combinaciones.

\begin{tabular}{|l|c|c|c|c|c|c|c|c|}
\hline & $\mathbf{X V}$ & $\mathbf{X V I}$ & $\mathbf{X V I I}$ & $\mathbf{X V I I I}$ & $\mathbf{X I X}$ & $\mathbf{X X}$ & Total & Observaciones \\
\hline Las de & $\begin{array}{c}1 \\
\text { Villadiego }\end{array}$ & 17 & 37 & 6 & 20 & 46 & 127 & \\
\hline Tomarlas & & $\begin{array}{c}3 \\
(1545)\end{array}$ & $\begin{array}{c}2 \\
(1625)\end{array}$ & & & & 5 & \\
\hline Afufarlas & & $\begin{array}{c}1 \\
(1599)\end{array}$ & 6 & 2 & 2 & & 11 & \\
\hline Apeldarlas & & & $\begin{array}{c}5 \\
(1617- \\
1672)\end{array}$ & & & & 5 & \\
\hline Liarlas & & $\begin{array}{c}5 \\
(1624)\end{array}$ & $\begin{array}{c}1 \\
(1625)\end{array}$ & & $\begin{array}{c}1 \\
(1844)\end{array}$ & & 6 & $\begin{array}{c}\text { El ejemplo del XIX } \\
\text { es 'liárselas' }\end{array}$ \\
\hline Volarlas & & & & & $\begin{array}{c}1 \\
(1883)\end{array}$ & $\begin{array}{c}3 \\
(1970)\end{array}$ & 4 & 1 \\
\hline Guillárselas & & & & & $\begin{array}{c}1 \\
(1892)\end{array}$ & & 1 & \\
\hline Tocárselas & & & & & & 17 & 17 & \\
\hline Pirárselas & & & 56 & 8 & 25 & 66 & 177 & \\
\hline & 1 & 21 & $5644)$ & & \\
\hline
\end{tabular}

TABLA 1: Primera datación y cronología de las combinaciones analizadas según los datos de corpus.

\section{CONCLUSIONES}

Tras el recorrido histórico que hemos efectuado de la construcción pirárselas, y similares, la conclusión a la que hemos llegado resulta clara: el origen del clítico femenino, es decir, el sintagma nominal correferente del mismo, tuvo que ser las calzas, a partir de la construcción tomar las calzas de Villadiego, construcción datada a finales del siglo XV y que llega hasta la actualidad, si bien en el siglo XVI alternaba la forma tomar las calzas de Villadiego con tomar las de Villadiego, siendo esta 
última estructura gramaticalizada la que acabó triunfando, y ya a partir del siglo XVII no hay testimonios, en el corpus utilizado, de la estructura completa. Gracias a un proceso de subjetivación, en el siglo XVI aparece la construcción tomarlas, en la que el clítico femenino no hace referencia explícita a ningún sintagma nominal, quedando convencionalizado el significado de la construcción desde un significado basado en situaciones extralingüísticas identificables más o menos objetivamente (relación de correferencia con un sintagma nominal previo), hacia un significado convencionalizado basado en la actitud del hablante o en su creencia sobre lo que se dice (el valor de desplazamiento). La subjetivación muestra cómo el significado pragmático (la relación de correferencia implicada con calzas, pero no dada de forma explícita) puede llegar a gramaticalizarse y convertirse, por tanto, en una construcción convencional: desplazamiento. Este proceso de subjetivación muestra una serie de restricciones en el comportamiento sintáctico de la construcción, consistente no ya en el debilitamiento, sino en la cancelación de la capacidad sintáctica del clítico femenino, al dejar de tener correferencia con sintagma nominal alguno, es decir, hay un aislamiento sintáctico y cancelación de la sintaxis, consecuencia de la naturaleza del proceso de subjetivación. Este debilitamiento de la estructura argumental de la oración, al carecer de referencia explícita el clítico femenino de complemento directo, supone también un debilitamiento de las relaciones entre los constituyentes del enunciado subjetivo, que solo admite una interpretación global, y no a través del significado de sus constituyentes individuales: se convencionaliza un significado de desplazamiento por medio de una construcción intransitiva, lo cual es totalmente absurdo (a no ser que se reconstruya el proceso de subjetivación y lleguemos históricamente al sintagma nominal implicado: las calzas). Evidentemente el valor del clítico gramaticalizado incide sobre la oración en su conjunto, y no sobre alguno de los constituyentes del mismo. Consecuencia, igualmente, de esta fijación, aislamiento y autonomía predicativa es la reducción de la capacidad relacional de las formas sometidas a subjetivación, lo que podía conducir incluso al hecho de formar expresiones fijas, según Company (2004). Debemos recordar, nuevamente, que las construcciones con clítico femenino fosilizado son consideradas, en general, por la fraseología, locuciones, es decir, expresiones fijas. Señalaba Company igualmente la posibilidad de otra característica semántica en los procesos de subjetivación: el debilitamiento del significado referencial etimológico originario, es decir, el vaciamiento en algún grado del significado referencial etimológico originario, lo que provoca nuevos significados más abstractos que entran en nuevos contextos, distintos de los originales. Evidentemente este proceso semántico se produce también en tomarlas, y de forma doble, pues, por un lado, nos encontramos con la evolución del significado de la construcción tomar las calzas de Villadiego hasta el valor metonímico 
de 'desplazamiento', y, por otro, con el significado de tomarlas, en el que se pierde toda conciencia de sintagma nominal alguno en función de complemento directo, $\mathrm{y}$ el significado es identificado con 'desplazamiento'. También podríamos suponer una mayor expresividad en la construcción, quizás en este caso meramente especulativa, debido a la falta de testimonios y la poca vida del término, pero debemos recordar que, en general, las construcciones con clítico femenino fosilizado están marcadas expresivamente con un valor que va desde lo coloquial o familiar, hasta lo vulgar.

La explicación de la subjetivación dada sirve, como hemos dicho, para dar cuenta de la construcción tomarlas. Sin embargo, ya hemos visto que dicho término tuvo poco éxito en la historia de la lengua (si bien el hecho de que Correas lo recogiera nos puede dar muestra de su frecuencia de uso), pues no hay testimonios más allá del siglo XVII. Por ello, la explicación para la presencia del clítico femenino en construcciones como afufarlas, apeldarlas, liarlas y volarlas tuvo que ser la analogía con la forma tomarlas. Todas estas construcciones parten de verbos previos con el significado dado de 'desplazamiento'. El valor intensificador y expresivo del clítico femenino, y su propia presencia, solo puede explicarse por una relación analógica con tomarlas, al compartir el significado de desplazamiento. El éxito de todas estas construcciones fue diverso, pues mientras afufarlas surgió a finales del XVI y llega en la documentación histórica trabajada hasta finales del siglo XIX, apeldarlas, liarlas y volarlas se atestiguan en el siglo XVII, y en el caso de volarlas de forma poco frecuente, si bien hemos acreditado un ejemplo de liarlas (liárselas) en el siglo XIX, lo cual puede ser síntoma de que, aunque poco frecuente, quizás por el tipo de registro utilizado, su uso se extendió hasta entonces. Siendo esto así, entonces, la aparición a finales del siglo XIX de las construcciones guillárselas y tocárselas, a partir, al igual que las formas anteriores, de verbos con significado ya dado de desplazamiento, tuvo que venir motivada por relación analógica también, pero no directamente sobre tomarlas, que ya no se usaba en el XIX, sino sobre afufarlas, que llega acreditado en el corpus hasta finales del XIX, coincidiendo con la aparición de las formas anteriores. Si bien tocárselas es locución poco frecuente, guillárselas acredita su uso hasta finales del siglo XX. Por tanto, y teniendo en cuenta que pirárselas se construye a partir de un verbo con significado de desplazamiento ya dado, pirar, la presencia del clítico femenino en pirárselas puede explicarse por analogía con guillárselas, que es la forma con la que coincide en el tiempo. Así pues, la relación de pirárselas con tomarlas no es directa, sino que viene mediada por otras relaciones analógicas con construcciones similares, fundamentalmente afufarlas y guillárselas. La impresión que tenemos es que la analogía no solo viene dada por una comunidad de significado, desplazamiento, sino por un contexto de uso. Es decir, no solo es el significado de 
desplazamiento el que genera la relación analógica, sino también el valor coloquial o familiar de la construcción, dada la expresividad de las locuciones consideradas. Por otro lado, y teniendo en cuenta el recorrido analizado, no estamos ante un caso de analogía aislada, es decir, restringida a un elemento concreto, sino que son muchos los elementos implicados en las relaciones analógicas, lo cual es muestra de una productividad de la misma.

Quedaría por dilucidar la influencia analógica de las construcciones con clítico femenino en su conjunto, pero para ello habría que ampliar los objetivos del presente trabajo al conjunto de las construcciones con clítico femenino fosilizado. En cualquier caso, lo que es seguro es que estamos ante una regla plenamente productiva que permite dar cuenta no ya de cambios construccionales, sino de un proceso de construccionalización: las construcciones con clítico femenino fosilizado. Y el caso de las formadas con clítico femenino plural, y más concretamente, las integradas por verbos de desplazamiento, no son otra cosa sino subesquemas de dicha construccionalización.

\section{BIBLIOGRAFÍA}

Albano, H \& Ghío, A. (2013): "Construcciones de ir + clítico le/la en el español de Buenos Aires", Traslaciones. Revista Lationamericana de Lectura y Escritura 1/1, pp. 92-105.

Blevins, J. P. \& Blevins, J. (2009): "Introduction: Analogy in grammar", in J. P. Blevins \& J. Blevins (eds.): Analogy in Grammar. Form and Acquisition, Oxford: Oxford University Press, pp. 1-12. https://doi.org/10.1093/acprof:oso/9780199547548.003.0001

Bools, G. (2010): Construction Morphology, Oxford: Oxford University Press.

Bybee, J., Perkins, R. \& Pagliuca, W. (1994): The evolution of grammar, Chicago: The University of Chicago Press.

CASARES, J. (1969): Introducción a la lexicografía española, Madrid: CSIC.

Casas Gómez, M. (1986): La interdicción lingüistica. Mecanismos del eufemismo y disfemismo, Cádiz Universidad de Cádiz.

Company, C. (2003): "La gramaticalización en la historia del español”, Medievalia 35, pp. 3-61.

Company, C. (2004): "Gramaticalización por subjetivización como prescindibilidad de la sintaxis", Nueva Revista de Filología Hispánica LII/1, pp. 1-27. https://doi.org/10.24201/nrfh.v52i1.2226 
Cordero Monge, S. \& LeOni de LeÓn, J. A. (2017): "Locuciones verbales con clítico: ejemplos del español de Costa Rica", Nuevos estudios sobre comunicación social, Santiago de Cuba: Centro de Lingüística Aplicada, pp. 152-155.

Corominas, J. \& Pascual, J. A. (1987): Diccionario crítico etimológico castellano e hispánico, Madrid: Gredos.

Сномsкy, N. (1989): El conocimiento del lenguaje. Su naturaleza, orígenes y uso, Madrid: Alianza.

De Smet, H. \& Verstraete, J. C. (2006): "Coming to terms with subjectivity", Cognitive Linguistics 17/3, pp. 365-392. https://doi.org/10.1515/COG.2006.011

De Smet, H. (2009): “Analysing reanalysis”, Lingua 119/11, pp. 1728-1755. https:// doi.org/10.1016/j.lingua.2009.03.001

DelbecQue, N. (1997): "De la funcionalidad del clítico femenino plural en locuciones verbales”, Revista de Filología Románica 14/I, pp. 211-224.

Elvira, J. (1998): El cambio analógico, Madrid: Gredos.

Elvira, J. (2010): Lingüistica histórica y cambio gramatical, Madrid: Síntesis. https:// doi.org/10.3726/978-3-0351-0519-3

FERTIG, D. (2013): Analogy and Morphological Change, Edinburgo: Edinburgh University Press.

Fischer, O. (2007): Morphosyntactic Change: Functional and Formal Perspectives, Oxford: Oxford University Press.

FisCHER, O. (2010): “An analogical approach to grammaticalization”, in G. Stathi \& E. König (eds.): Grammaticalization: Current Views and Issues, Amsterdam: John Benjamins, pp. 181-220. https://doi.org/10.1075/slcs.119.11fis

Fischer, O. (2016): "Morphosyntactic change", in M. Kytö \& P. Pahta (eds.): The Cambridge Handbook of English Historical Linguistics, Cambridge: Cambridge University Press, pp. 237-255.

García Benito, A. B. (2009): "Locuciones con clítico de objeto directo en portugués", Limite 3, pp. 7-25.

García Page, M. (2008): Introducción a la fraseología española, Barcelona: Anthropos.

García PAGe, M. (2010): "Locuciones verbales con clítico es español del tipo dársela", Verba hispánica 18, pp. 135-145.

Ghesquière, L., Brems, L. \& VAN DE Velde, F. (2014): "Intersubjectivity and intersubjectification. Typology and operationalization”, in L. Brems, L. Ghesquière \& F. Van de Velde (eds.): Intersubjectivity and Intersubjectification. Grammar and 
Discourse, Amsterdam: John Benjamins, pp. 129-153. https://doi.org/10.1075/ bct.65.07ghe

Ghío, A. y Albano, H. (2013): “'Locuciones verbales' con pronombre personal átono la/las en el español coloquial de Buenos Aires”, Gramma XXIV, 51, pp. 102-116. Halliday, M. \& Hasan, R. (1976): Cohesion in English, Londres: Longman.

HoRN, L. R. (1984): “Toward a new taxonomy for pragmatic inference: Q- and R-based implicatura", in D. Shiffrin (ed.): Meaning, form and use in context, Washington: Georgetown University Press, pp. 11-42.

IrIBARRen, J. M. (1994): El porqué de los dichos. Sentido, origen y anécdota de los dichos, modismos y frases proverbiales de España con otras muchas curiosidades, Pamplona: Gobierno de Navarra.

ItKonen, E. (2005): Analogy as Structure and Process, Amsterdam: John Benjamins. https://doi.org/10.1075/hcp.14

LANGaCKer, R. W. (1990): “Subjectification”, Cognitive Linguistics 1/1, pp. 5-38. https://doi.org/10.1515/cogl.1990.1.1.5

LANGACKER, R. W. (1993): "Deixis and Subjectivity", in S. K. Verma \& V. Prakasam (eds.): New Horizons in Functional Linguistics, Hyderabad: Booklinks Corporation, pp. 43-58.

LANGACKER, R. W. (1999): "Losing control: Grammaticization, subjectification, and transparency", in A. Blank \& P. Koch (eds.): Historical Semantics and Cognition, Berlín: Mouton de Gruyter, pp. 147-175. https://doi. org/10.1515/9783110804195.147

Levinson, S. C. (2004): Significados presumibles. La teoría de la implicatura conversacional generalizada, Madrid: Gredos.

MARINER, S. (1968): "El femenino de indeterminación", in Quilis, A., Carril, R. \& Cantarero, M. (eds.). Actas del XI Congreso Internacional de Lingüistica y Filología Románica, vol. III, pp. 1297-1314, Madrid: Revista de Filología Española.

MARINER, S. (1973): "Situación del neutro románico en la oposición genérica”, Revista Española de Lingüística 3/1, pp. 23-38.

Mattiello, E. (2017): Analogy in Word-Formation. A Study of English Neologisms and Occasionalisms, Berlin: De Gruyter-Mouton. https://doi. org $/ 10.1515 / 9783110551419$

ORDUÑA LÓPEZ, J. L. (2011): "Estudio gramatical de las locuciones verbales con doble pronombre clítico”, Revista de Lingüística Teórica y Aplicada 49/2, pp. 87-110. https://doi.org/10.4067/S0718-48832011000200005 
R.A.E. (2014): Diccionario de la Lengua Española, Madrid: Espasa-Calpe.

R.A.E. (2009): Real Academia Española y Asociación de Academias de la Lengua Española, Nueva Gramática de la Lengua Española, Madrid: Espasa, 2 vols.

RAINER, F. (2013): "Formación de palabras y analogía: aspectos diacrónicos", in I.

Pujol Payet (ed.): Formación de palabras y diacronía, La Coruña: Universidad de La Coruña, pp. 141-172.

SPITzER, L. (1941): “Feminización del neutro", Revista de Filología Hispánica III/1, pp. 339-371.

Traugott, E. C. (1982): "From propositional to textual and expressive meanings: Some semantic-pragmatic aspects of grammaticalization", in W. P. Lehmann \& Y. Malkiel (eds.): Perspectives on historical linguistics, Amsterdam: John Benjamins, pp. 245-271. https://doi.org/10.1075/cilt.24.09clo

Traugott, E. C. (1989): “On the rise of epistemic meanings in English: An example of subjectification in semantic change", Language 65/1, pp. 31-55. https://doi. org/10.2307/414841

Traugott, E. C. (1995): "Subjectification in grammaticalization", in D. Stein \& S. Wright (eds.): Subjectivity and subjectivisation. Linguistic perspectives, Cambridge: Cambridge University Press, pp. 31-54. https://doi.org/10.1017/ CBO9780511554469.003

Traugott, E. C. (1996): "Subjectification and the development of epistemic meaning: The case of promise and threaten, in T. Swan \& O. J. Westvik (eds.): Modality in Germanic Languages, Berlín: Mouton de Gruyter, pp. 185-210.

Traugott, E. C. \& Dasher, R. B. (2002): Regularity in Semantic Change, Cambridge: Cambridge University Press.

TraugotT, E. C. \& KöNIG, E. (1991): “The semantics-pragmatics of grammaticalization revisited", in E. C. Traugott \& B. Heine (eds.): Approaches to Grammaticalization, 1, Amsterdam: John Benjamins, pp. 189-218. https://doi.org/10.1075/ ts1.19.1.10clo

Traugott, E. C. \& Trousdale, G. (2013): Constructionalization and Constructional Changes, Oxford: Oxford University Press. https://doi.org/10.1093/acprof:oso/9780199679898.001.0001

Zamora Salamanca, F. J. (1984): "La tradición histórica de la analogía lingüística", Revista Española de Lingüística 14/2, pp. 367-419. 